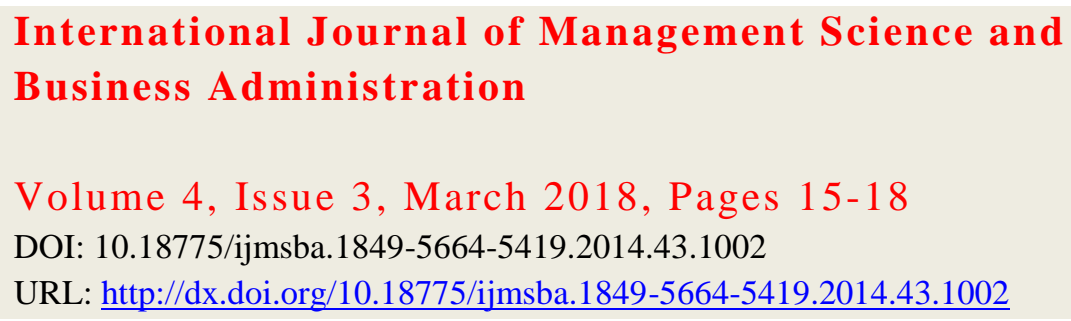

\title{
A Quantitative Approach to Existing Issues of Audit Planning in Appropriateness and Relevance Analysis
}

\author{
Isroil Ismoilovich Meliyev \\ Department of Audit, Tashkent Institute of Finance, Uzbekistan
}

\begin{abstract}
Audit planning has been a key stage of the audit process, which depicts the trajectory and basic actions. Developments in business and audit itself gave an impetus for the upgrading the audit plan regarding coverage, quality, and risk assessment. In turn, reshaped audit planning practices enriched with particular requirements and elements. However, qualitative measures are still failing to provide the clarity and credibility of audit plan compliance, which reveals the existence of a need for a quantitative approach. This article investigates the existing problems in current practices of audit planning and proposes a quantitative method for measuring the appropriateness and relevance of an audit plan.
\end{abstract}

Keywords: Audit planning, Appropriateness, Relevance, Quantitative

\section{Introduction}

To form an appropriate basis for expressing an opinion on the financial statements, the auditor must plan and perform the audit to obtain reasonable assurance about whether the financial statements are free of material misstatement due to error or fraud (PCAOB, 2010). The risk in auditing activity derives from different sources, origins, and reasons, but the most probably from improper timing and sequence of auditing procedure. Consequent misstatement brings to the loss of the credibility for auditor's statement and increases the operational and investment risks. In international practice, leading audit companies strictly follow audit planning principles and procedures for trustable quality auditor report. Thanks to the adequately set audit plan and audit strategy they keep their power in auditing services market and promote the service quality. Studies over developments in auditing practices revealed that advanced audit planning had become a nearly common practice among international audit companies.

The advanced auditing process is a complicated but prudent technique of guaranteeing the minimum-risk auditor reports. The advanced audit process is comprised of three important stages: pre-audit, audit and post audit. Audit planning is the initial and the most important sub-stage in the pre-audit stage. As audit services also expand in quality, scope and coverage, prerequisite pre-audit operations introduced into practice. Pre-audit activities not only reduce the audit risk but also facilitates the closeness of auditor's to the company. Audit companies and individual auditors do not equally follow it because of non-mandatory status. However, internationally recognized audit companies have already made it obligatory to ensure quality and clear auditing results.

The cornerstone of the pre-audit stage is audit planning and strategy, which sets the specifics and a preliminary program of audit check-ups. In planning the auditing process, an auditor must prepare the audit strategy and plan. Strategy-making is the general measure for setting the overall principles, rules, and procedures inconsistent with company's operational environment, area and other specific attributes, which may impact on the financial profile. Audit plan highlights the precise actions, steps, and sequence of operations, timing, and targets of the individual auditor or auditing team. Audit planning process plays an essential role in ensuring the reliable, relevant and useful results for client's smooth and efficient business. An appropriately set audit plan lays the foundation for clear and credible audit findings, which are a clue for making strategic management and investment decisions. 
Recent developments in corporate management led to the rethinking of audit planning practices and methods by putting new objectives and requirements. In the new horizon of audit planning comprehensiveness, appropriateness, relevance, and risk mitigation have become the prerequisites of audit planning. In line with structural changes in audit planning methods, growing need for qualitative requirements. International accounting and auditing organizations, audit companies and research institutes proposed several standards and quality requirements for audit plan and audit strategy. Due to their consultative manner, limited coverage and lack of fit to national accounting and auditing systems of some countries, qualitative requirements have not been introduced into practice. In line with qualitative limitations, quantitative requirements in audit planning are remaining unsolved and unclear. A complete set of indicators, methodologies, and criteria have not been applied to professional auditing activity yet. Despite several attempts, a comprehensive set of quantitative indicators does not exist, and quantification of appropriateness and relevance is impossible. Considering the growing necessity for credibility and appropriateness of audit results in a contemporary business community, audit planning practices and methods face new challenges in meeting modernity, fit and comprehensiveness requirements.

Majority of abovementioned issues derived from the lack of scientific roots and fundamentals, poor interconnectedness with business environment and weaknesses in global policymaking. To reveal the current scenario of appropriateness, relevance, and risk mitigation capacity of audit planning practices, this article strongly focused on the defining the key requirements and the quantitative assessment of audit planning to ensure comparability and efficiency. Using empirical methods, specific audit plan appropriateness and relevance assessment method is proposed and adapted to the core characteristics of the modern business environment.

\section{Statement of Problem}

Audit planning is a widely known and commonly applied practice in the auditing process. Practitioners know the advantages of audit plan and strategy, but they usually do not assess the extent of its impact on the risk mitigation and quality. From the scientific point of view, audit plan is an untouched area of research due to its pure practical character. Search for in-depth studies revealed that there is a very limited number of previous studies in audit planning. Therefore, existing problems have not been scientifically investigated, and possible solutions have not been proposed yet. In this research, an author traced the roots of following issues.

By generally accepted view, audit planning is a non-obligatory method of mitigating risk and ensuring the quality. Hence clear-cut sequence, principles, and requirements for audit plan still do not exist. Auditors possess freedom in setting the plan and strategy, which are not evaluated regarding fit and appropriateness. In some cases, an audit plan does not bring any results due to a mismatch between actual auditing process and sometimes shows differentiating or contrary actions.

In practice, audit plan is more effective, when auditing process conducted by a team of auditors. When a company is audited by a sole auditor, he may decide not to set audit plan and conducts the auditing activity freely depending on the situational needs. Consequently, an auditor may face three potential problems: (a) time mismanagement, (b) omit and (c) poor audit quality. To address these problems, audit planning has no mandatory character.

In auditing process, auditors are accustomed to checking the appropriateness and credibility of financial operations of the client and are limited to analyze the perspectives, potential risks, and hazards.

\section{Research Methodology}

An audit plan is assessed more with qualitative criteria rather than quantitative ones. Its impact on audit quality and risk management is also out of focus and practically not measured anywhere without any methods. This research is aimed to conduct the quantitative analysis of audit plan from different standpoints. Quantitative analysis is sequenced in two stages, where the first stage serves as a generator of input data for the second stage. The first stage is structured around scaling \& scoring method in Likert style. Qualitative measures are converted into quantitative ones through scaling. Impact of audit plan is divided into three categories, and in turn, each category is grouped into subcategories (Table 1). Audit plan's impact on risk management is grouped into three risk types, classified as sub-categories: (a) business risk, (b) inherent risk, (c) control risk. Audit plan's imp[act on audit quality is evaluated through four impact channels, reflecting different aspects of audit quality parameters: (a) auditor's experience, (b) auditor's acceptance, (c) understanding of client's business, (d) understanding of client's industry. Coverage of audit plan is also a point of 
estimation due to the importance of auditing operations and analysis for the decision-makers and investors. Therefore, audit plan coverage is assessed regarding engagement, performance management, vulnerability, and sensitivity.

Table 1: Scaling \& scoring table

\begin{tabular}{|l|l|c|}
\hline Category & Sub-categories & Criteria \\
\hline \multirow{4}{*}{ Risk } & Business risk (BR) & $0-4$ \\
\cline { 2 - 3 } Auditor quality & Inherent risk (IR) & $0-4$ \\
\cline { 2 - 3 } & Control risk (CR) & $0-4$ \\
\hline & Auditor's experience (AE) & $0-4$ \\
\cline { 2 - 3 } & Auditor's acceptance (AA) & $0-4$ \\
\cline { 2 - 3 } & $\begin{array}{l}\text { Understanding of client's corporate } \\
\text { environment (UC) }\end{array}$ & \multicolumn{2}{|c|}{$0-4$} \\
\cline { 2 - 3 } & Understanding of client's industry (UI) & $0-4$ \\
\hline \multirow{5}{*}{ Coverage } & Audit engagement (AN) & $0-4$ \\
\cline { 2 - 3 } & $\begin{array}{l}\text { Analytical approach to performance } \\
\text { management (AP) }\end{array}$ & $0-4$ \\
\cline { 2 - 3 } & Vulnerability assessment (VA) & $0-4$ \\
\cline { 2 - 3 } & Sensitivity assessment (SA) & $0-4$ \\
\hline
\end{tabular}

Table 2: Likert style scale

\begin{tabular}{|c|c|}
\hline Scale & Significance \\
\hline $3,001-4$ & Highly appropriate and relevant \\
\hline $2,001-3$ & Appropriate and relevant \\
\hline $1,001-2$ & Slightly appropriate and relevant \\
\hline $0,001-1$ & Inappropriate and irrelevant \\
\hline 0 & Absolutely inappropriate and irrelevant \\
\hline
\end{tabular}

The mathematical model of the proposed assessment methodology is based on a chain of the geometric mean. The model enables to evaluate the impact of audit planning on each category. Key indicator quantifies the overall appropriateness and relevance of audit planning. Appropriateness and relevance coefficient is the composite geometric mean of coefficients of categories.

$$
\left(\prod_{i=1}^{n} x_{i}\right)^{\frac{1}{n}}=\sqrt[n]{x_{1} * x_{2} * \ldots * x_{n}}
$$

\section{Quantitative Approach to Appropriateness and Relevance of an Audit Plan}

The proposed model enables the auditor to sophisticate the audit plan before conducting the audit. If there is a need for comparing the expected and completed auditing results, an auditor or an auditing team may compare the plan and actual estimations.

Mathematical specifics of the model is based on the method of chain mean average of each type or subcategories. Final/ categorical/ sub-categorical assessments are be calculated as follows. 
The impact of audit plan on risk mitigation:

$$
R M=\sqrt[3]{B R * I R * C R}
$$

The coefficient of the impact of audit plan on risk management ranges from 0-4 and follows the same criterion as shown in Table 1.

$$
A Q=\sqrt[4]{A E * A A * U C * U I}
$$

The coefficient of the impact of audit plan on audit quality ranges from 0-4 and follows the same criterion as shown in Table 1.

The coefficient of audit coverage:

$$
A C=\sqrt[4]{A N * A P * V A * S A}
$$

The composite coefficient of the appropriateness of audit plan:

$$
A A P=\sqrt[3]{R M * A Q * A C}
$$

The coefficient of the impact of audit plan on risk management ranges from 0-4 and follows the same criterion as shown in Table 1.

\section{Conclusion}

Quantitative approach has a limited capacity to tackle issues of measuring the extent of relevance and appropriateness of audit plan. However, this research attempts to present a primary view of quantitative methods. Clarity, credibility, and objectivity of scoring and scaling need further research improvements. Furthermore, mentioned means of quantification could not address key problems: they need structural reforms and systemic changes. Considering the current stance of audit planning practices, following recommendations are proposed to enhance the efficiency, appropriateness, and relevance of audit planning.

It is highly recommended to set specific requirements for the quality, appropriateness, and relevance of audit plans, to avoid mismatches and uselessness, differences and contrary facts, derived from inappropriate of audit plans, a growing need for qualitative, fit and appropriateness requirements.

To address existing problems, especially time mismanagement, omittance and poor audit quality, audit planning is advised to be mandatory, if auditing process is conducted by a team of auditors.

Risk and prospective analyses are of business analysis area, but an audit can provide at least primary signals of vulnerability, sensitivity and performance indicators. If these indicators are included in audit plan, decision-makers and investors obtain a valuable data.

\section{References}

- Bingham, K. (2012). Contemporary Practices in Risk Management: Implementation Ideas from Leading Companies. IAA \& Audit Executive Center Publications.

- Burke, A. (2011). Introduction to Audit Planning. CPA Ireland Study Support Materials.

- Chartered Institute of Internal Auditors (2014). Risk based internal audit planning. CIIA Standards Guide.

- IACOP (2014). Risk assessment in audit planning: a guide for auditors on how to best assess risks when planning audit work. PEMPAL- IACOP Publications.

- ICAEW (2015). Risk assessment and internal controls: continuing challenges for auditors. International Auditing Perspectives Series, IAAE, ICAEW.

- PCAOB. (2010). AS2101: Audit Planning. PCAOB Release No. 2010-004. PCAOB Publications.

- Tall-Verifika, U. et al. (2002). Quality in the Audit Process, Volume 1. SAI Publications.

- Tay, S. (2017) Risk Management in Internal Audit Planning. In: Tan C., Goh T. (eds) Theory and Practice of Quality and Reliability Engineering in Asia Industry. Springer, Singapore Crossref. 